\title{
Impact of Lamivudine plus Adefovir therapy in chronic hepatitis B Iranian patients, resistant to Lamivudine treatment alone, on disease inhibition: A pilot study
}

\author{
Arezoo Estakhri, Ashraf Mohamadkhani, Hosein Poustchi, Ghodrat Montazeri \\ Digestive Disease Research Institute (DDRI), Shariati Hospital, Tehran University of Medical Sciences, Tehran, Iran \\ Email: arezooestakhri@yahoo.com
}

Received 12 December 2011; revised 16 February 2012; accepted 18 February 2012

\begin{abstract}
AIM: To evaluate the impact of combination therapy with Lamivudine and Adefovir for treatment of chronic hepatitis B in Lamivudine-resistant patients. METHODS: Among the $\mathbf{1 1 0}$ adult chronic hepatitis $B$ Iranian patients whom were treated with Lamivudine, for 36 months, nineteen patients (17\%) with no any biochemical and viral responses to Lamivudine alone, were selected and enrolled in the study. Due to resistancy, Adefovir was added to Lamivudine, and continued for 30 months. We measured HBV_DNA viral load and serum AST, ALT in 0, 12, 24, 30 and 0, 6, 12, 18, 24, 30 months, respectively. RESULTS: Between biochemical and viral characteristics, Repeated Measure analysis identified just biochemical markersAspartate Aminotransferase level (AST) (P = 0.002) and Alanine Aminotransferase level (ALT) $(P=0.007)$ -as predictors of response to treatment, while, viral marker-HBV DNA load-was not statistically significant ( $P=0.128)$. CONCLUSIONS: Treatment for a long time, such as $21.5 \pm 8.8$ months, with Lamivudine and Adefovir, can cause liver enzymes including AST and ALT, decreasing and being normal. But, this finding is not indicative, for HBV-DNA viral load.
\end{abstract}

Keywords: Adefovir Dipivoxil; Lamivudine-Resistant; Chronic Hepatitis B; Combination Treatment

\section{INTRODUCTION}

Chronic hepatitis B is one of the main causes of liver damage such as liver cirrhosis and hepatocellular carcinoma [1]. But, these events can be prevented by appropriate therapy. There are five approved (1998-2008) nucleos(t)ide analogues, for hepatitis B treatment. One of them, which is very common and has been used as the first line therapy for several years, is Lamivudine. The main problem with this drug is increasing resistancy more than $65 \%$ in five years treatment [2]. Another important issue, is lower potency of using antiviral drugs, separately, compared with administration together. Studies show that adding the second drug like Adefovir, to Lamivudine, can lead to desired results [3]. In order to evaluate the efficacy of Lamivudine plus Adefovir therapy with regards to prevent long-term mentioned harms of disease, in patients with resistancy to Lamivudine alone, we performed this study.

\section{PATIENTS AND METHODS}

\subsection{Patients}

From March 2006 to March 2009, a total of 110 adult patients with chronic hepatitis B were treated with Lamivudine in our outpatient clinic. Among them, nineteen patients (17\%) developed resisitancy (YMDD mutant) and were enrolled in the study. YMDD mutation, was confirmed by Direct Sequencing. Then, Adefovir was added to Lamivudine. Treatment with two drugs lasted, $21.5 \pm 8.8$ months. Inclusion criteria for selecting patients and no response to Lamivudine alone, were: 1) Liver enzymes specially ALT, more than $60 \mathrm{IU} / \mathrm{L}$ after a period of being in normal range (at least: 2.5 years); 2) High level of HBV-DNA [more than $10^{5}$ copies/mL] in 2 times checking (at least: 6 months) after a period of being in normal range.

\subsection{Methods}

At first, all of 110 patients received Lamivudine alone with a dose of $100 \mathrm{mg} /$ daily for 3 years. Among them, patients with resistancy to the first drug, were selected and treated with two drugs, Lamivudine and Adefovir (10 mg/daily) for 30 months. Liver function tests, including AST and ALT, were measured every 6 months after adding the second drug. Moreover, HBV-DNA viral load was assessed each 12 months, for 36 months, by Real Time PCR assay (Taqman). All patients provided 
written informed consent before therapy was given.

\subsection{Statistical Analysis}

We recorded and analyzed our data by using SPSS (version 16, Inc, Chicago, IL). Repeated measure test was used to evaluate the changes of both, biochemical and virological markers, during 36 months of combination treatment.

A $\mathrm{P}$ value of less than 0.05 was considered to be statistically significant.

\section{RESULTS}

\subsection{Baseline Characteristics of Patients}

The baseline characteristics of the patients are shown in Table 1.

\subsection{Changes of AST, ALT and HBV-DNA Levels by Two Drugs Treatment}

As in Table 2, serum AST and ALT levels were normalized after 30 months treatment with Lamivudine and Adefovir (Figures 1 and 2). While, there is no any good changes in serum HBV-DNA levels. This means that, the level of serum HBV-DNA has been low in 12 and 30 months, while it has been high in 24 months of combination treatment (Figure 3).

\section{DISCUSSION}

There are several studies about combination treatment with Lamivudine and Adefovir in chronic hepatitis B [4], HBeAg negative patients, resistance to Lamivudine

Table 1. Baseline characteristics of patients.

\begin{tabular}{lc}
\hline Age $(\mathrm{yr})$ & $44.7 \pm 8.1$ \\
Male & $68.4 \%$ \\
Female & $31.6 \%$ \\
Duration of combination treatment (months) & $30.2 \pm 5.3$ \\
Baseline ALT & $188.4 \pm 224.0$ \\
Baseline HBV-DNA $\left(\log _{10} \mathrm{Copy} / \mathrm{ml}\right)$ & $1.98 \mathrm{E} 7 \pm 5.75 \mathrm{E} 7$ \\
\hline
\end{tabular}

Estimated Marginal Means of MEASURE_1



Figure 1. Changes of serum AST levels during 30 months combination treatment.

Estimated Marginal Means of MEASURE_1

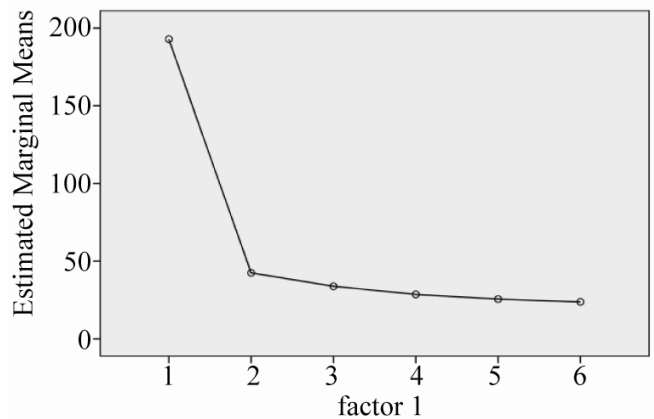

Figure 2. Changes of serum ALT levels during 30 months combination treatment.

Estimated Marginal Means of MEASURE_1

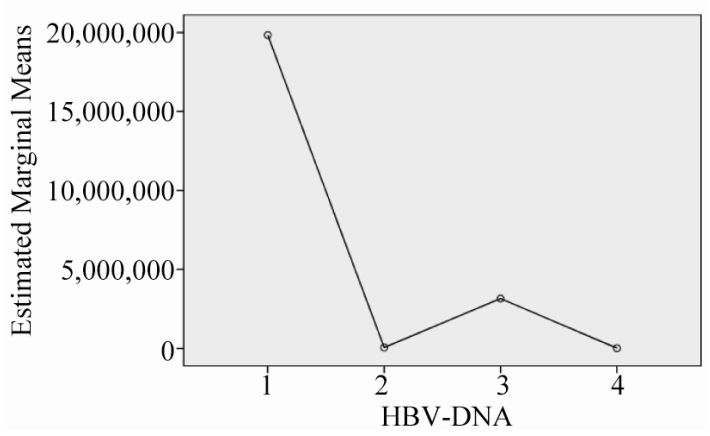

Figure 3. Changes of serum HBV-DNA viral load during 30 months combination treatment.

Table 2. Changes of mean serum ALT, AST and HBV-DNA levels during combination treatment.

\begin{tabular}{|c|c|c|c|c|c|c|}
\hline \multicolumn{7}{|c|}{ Months after adding Adefovir } \\
\hline \multirow{3}{*}{ P-Value (ALT) } & 0 & 6 & 12 & 18 & 24 & 30 \\
\hline & $188.4 \pm 224.0$ & $41.4 \pm 30.2$ & $33.4 \pm 24.9$ & $28.2 \pm 16.9$ & $24 \pm 10.9$ & $22.2 \pm 5.3$ \\
\hline & $\mathrm{S}$ & $\mathrm{S}$ & $\mathrm{S}$ & $\mathrm{S}$ & $\mathrm{S}$ & $\mathrm{S}$ \\
\hline \multirow{2}{*}{ P-Value (AST) } & $114.1 \pm 107.1$ & $31.8 \pm 11.4$ & $24.5 \pm 8.6$ & $24.5 \pm 7.7$ & $23.7 \pm 5.7$ & $22.2 \pm 5.3$ \\
\hline & $\mathrm{S}$ & $\mathrm{S}$ & $\mathrm{S}$ & $\mathrm{S}$ & $\mathrm{S}$ & $\mathrm{S}$ \\
\hline \multirow{2}{*}{ P-Value (HBV-DNA) } & $1.98 \mathrm{E} 7 \pm 5.7 \mathrm{E} 7$ & - & $5.5 E 4 \pm 209144.7$ & - & $3.15 \mathrm{E} 6 \pm 1.37 \mathrm{E} 7$ & $1.25 \mathrm{E} 4 \pm 53891.8$ \\
\hline & NS & NS & NS & NS & NS & NS \\
\hline
\end{tabular}

(HBV-DNA $\log _{10}$ copies/ml) 
alone. Also, it has been shown that the rate of resistancy in treatment with Adefovir is lower than Lamivudine [5]. On the other hand, there is no any robust consensus about long-term combination treatment in patients with resistancy to Lamivudine, alone [6]. So, we evaluated 19 patients with mentioned criteria, to assess the efficacy of 2 drugs long-term treatment [30 months].

There are several studies about short-term treatment with Lamivudine and Adefovir. Lui et al. [7] showed that 2 drugs treatment, for more than two months has better only virological response. Also, Akyildiz et al. [8] found that there was no any difference in virological and biochemical responses with and without adding Adefovir to Lamivudine for three months.

In another study, Rapti et al. [9] showed that, resistancy to Adefovir is less frequent, in combination therapy.

On the other hand, in another research, it was concluded that treatment with Adefovir plus Lamivudine is more effective in patients, with Lamivudine-resistant chronic hepatitis B [10]. Moreover, Buti M et al. [11] and Lampertico $\mathrm{P}$ et al. [12] in different studies found that, there are some factors like serum AST and HBVDNA levels, that predict virological and biochemical responses in combination therapy. However, in another two studies, it has been shown that Tenofovir is efficient for patients with Lamivudive-Adefovir resistant [13,14]. But, it needs more studies with a longer time.

On the other hand, some studies show that, adding Adefovir to Lamivudine in early stages of resistancy, is better than adding it, when, resistancy has been occurred for a long time [15].

Moreover, earlier studies have established that Adefovir is extremely effective in cases with Lamivudineresistance during 60 weeks of treatment [16].

Our study, includes small population, but gives the information about the response to long-term combination therapy, with Lamivudine and Adefovir in genotype D - Iranian patients, resistant to Lamivudine alone. These patients, showed biochemical response-decreasing serum AST and ALT levels (Figures 1 and 2)-however, incomplete response for decreasing of serum HBV-DNA viral load. In other words, viral load has had fluctuation, not constant decreasing level in serial months (Figure 3).

In conclusion, during long time such as 30 months, treatment with $\mathrm{ADF}$ and Lamivudine make liver enzymes—serum AST and ALT_-being in normal range, yet virological response is incomplete.

\section{REFERENCES}

[1] Kao, J.H. and Chen, D.S. (2002) Global control of hepatitis B virus infection. The Lancet Infectious Diseases, 2, 395-403. doi:10.1016/S1473-3099(02)00315-8
[2] Lok, A.S., Lai, C.L., Leung, N. and Yao, G.B. (2003) Long term safety of Lamivudine treatment in patients with chronic hepatitis B. Gastroenterology, 125, 17141722. doi:10.1053/j.gastro.2003.09.033

[3] Tziomalos. K. (2009) Combination treatment in HBe-Ag negative chronic hepatitis B. World Journal of Hepatology, 1, 43-47. doi:10.4254/wjh.v1.i1.43

[4] Peters, M.G., Hann, H.H., Martin, P. and Heathcote, E.J. (2004) Adefovir dipivoxil alone or in combination with Lamivudine in patients with Lamivudine-resistant chronic hepatitis B. Gastroenterology, 126, 91-101. doi:10.1053/j.gastro.2003.10.051

[5] Hadziyannis, S.J., Tassopoulos, N.C., Heathcote, E.J. and Chang, T.T. (2003) Adefovir dipivoxil for the treatment of hepatitis $\mathrm{B}$ e antigen-negative chronic hepatitis $\mathrm{B}$. The New England Journal of Medicine, 348, 800-807. doi:10.1056/NEJMoa021812

[6] Perrillo, R., Hann, H.W., Mutimer, D. and Willems, B. (2004) Adefovir dipivoxil added to ongoing Lamivudine in chronic hepatitis B with YMDD mutant hepatitis B virus. Gastroenterology, 126, 81-90. doi:10.1053/j.gastro.2003.10.050

[7] Lui, C.J., Kao, J.H., Chen, P.J. and Chen, T.C. (2006) Overlap Lamivudine treatment in patients with chronic hepatitis B receiving Adefovir for Lamivudine-resistant viral mutants. Journal of Viral Hepatitis, 13, 387-395. doi:10.1111/j.1365-2893.2005.00704.x

[8] Akyildiz, M., Gunsar, F., Ersoz, G. and Karasu, Z. (2007) Adefovir dipivoxil alone or in combination with Lamivudine resistant compensated chronic hepatitis B. Digestive Diseases and Sciences, 52, 3444-3447. doi:10.1007/s10620-006-9718-8

[9] Rapti, I., Dimou, E., Mitsoula, P. and Hadziyannis, S.J. ( 2007) Adding-on versus switching-to adefovir therapy in Lamivudine-resistant HBeAg-negative chronic hepatitis B. Hepatology, 45, 307-313. doi:10.1002/hep.21534

[10] Hosaka, T., Suzuk, F., Suzuki, Y. and Saithoh, S. (2004) Adefovir dipivoxil for treatment of breakthrough hepatitis caused by Lamivudine-resistant mutants of hepatitis B virus. Intervirology, 47, 362-369. doi:10.1159/000080881

[11] Buti, M., Elefsitionis, I., Jardi, R. and Vargas, V. (2007) Viral genotype and baseline load predict the response to Adefovir treatment in Lamivudine-resistant chronic heaptitis B patients. Journal of Hepatology, 47, 366-372. doi:10.1016/j.jhep.2007.04.011

[12] Lampertico, P., Vigano, M., Manenti, E. and Lavarone, M. (2007) Low resistance to Adefovir combined with Lamivudine: A 3-year study of 145 Lamivudine-resistant hepatitis B patients. Gastroenterology, 133, 1445-1451. doi:10.1053/j.gastro.2007.08.079

[13] Bommel, F.V., Wunsche, T., Mauss, S. and Reinke, P. (2004) Comparison of adefovir and tenofovir in the treatment of Lamivudine-resistant hepatitis B virus infection. Hepatology, 40, 1421-1425. doi:10.1002/hep.20464

[14] Bommel, F.V., Zollner, B., Sarrazin, C. and Spengler, U. (2006) Tenofovir for patients with Lamivudine-resistant hepatitis B virus (HBV) infection and high HBV DNA 
level during Adefovir therapy. Hepatology, 44, 318-325. doi:10.1002/hep.21253

[15] Lampertico, P., Vigano, M., Manenti, E. and Lavarone, M. (2005) Adefovir rapidly suppresses hepatitis B in HBe-Ag negative patients developing genotypic resistance to Lamivudine. Hepatology, 42, 1414-1419. doi:10.1002/hep.20939

[16] Westland, C.E., Yang, H., Delaney, W.E. and Wulfsohn, M. (2005) Activity of Adefovir dipivoxil against all patterns of Lamivudine-resistant hepatitis B viruses in patients. Journal of Viral Hepatitis, 12, 67-73. 